\title{
Analisis Kinerja Mesin dan Konsumsi Bahan Bakar Sepeda Motor dengan Variasi Kondisi Filter Udara
}

\author{
Kemas Muhammat Abdul Fatah ${ }^{(1)^{*}}$, Agus Pratama ${ }^{(1)}$ \\ ${ }^{(1)}$ Universitas Sang Bumi Ruwa Jurai \\ *email korespondensi: kmsmafattah@email.com
}

\begin{abstract}
Abstrak.
Peningkatan populasi kendaran bermotor dari tahun ke tahun akan seiring dengan peningkatan konsumsi BBM yang berasal dari minyak bumi, sumber energi tak terbarukan yang perlu dihemat dengan cara perawatan kendaraan motor, khususnya perawatan filter udara pada sepeda motor. Penelitian ini ditujukan untuk mengetahui kinerja mesin dan konsumsi bahan bakar pada kondisi filter yang berbeda jarak tempuh pemakaian sepeda motor, serta dapa menjelaskan pentingnya penggantian filter udara, dengan melakukan pengujian parameter daya, torsi dan konsumsi bahan bakar. Hasil penelitian menunjukkan bahwa pada kondisi filter $16000 \mathrm{~km}$, terjadi penurunan daya sebesar 8,28\% dan penurunan torsi sebesar 1,25\% dan peningkatan konsumsi bahan bakar sebesar 2,83\%. Penelitian ini juga dapat menjelaskan bahwa perawatan filter udara dengan hanya dibersihkan tidak mampu mengembalikan kinerja mesin, sehingga mengganti filter udara harus dilakukan.
\end{abstract}

Kata kunci: Daya, Filter Udara, Sepeda Motor, Torsi

\begin{abstract}
.
The increase in the population of motorized vehicles from year to year will be followed by the increase in consumption of fuel derived from petroleum, a non-renewable energy source that needs to be saved through motorcycle maintenance, especially air filter maintenance on motorcycles. This study aims to determine engine performance and fuel consumption under filter conditions with different mileage on a motorcycle and to explain the importance of replacing the air filter by testing power, torque and fuel consumption parameters. The results showed that at $16000 \mathrm{~km}$ filter conditions, there was a decrease in the power of $8.28 \%$ and a decrease in torque of $1.25 \%$, and an increase in fuel consumption of $2.83 \%$. This research can also explain that air filter maintenance by simply cleaning is not able to restore engine performance, so replacing the air filter must be done.
\end{abstract}

Keywords: air filter, motorcycle, power, torque

\section{PENDAHULUAN}

BBM adalah singkatan dari Bahan Bakar Minyak. Istilah ini sering digunakan untuk menyebut bahan bakar yang digunakan pada mobil dan sepeda motor. Padahal, penggunaan BBM sendiri tidak hanya terbatas pada kendaraan bermotor. Beberapa jenis BBM bahkan digunakan untuk jenis kendaraan lain seperti pesawat terbang dan untuk kendaraan bermotor umumnya menggunakan BBM jenis bensin.

Peningkatan populasi kendaran bermotor dari tahun ke tahun akan seiring dengan peningkatan konsumsi BBM. Tercatat pada tahun 2020, jumlah kendaraan bermotor secara nasional adalah 136,13 juta pada 2020 , atau naik $2,35 \%$ dari tahun sebelumnya, semetara realisasi konsumsi BBM nasional pada tahun yang sama mencapai 63,96 juta kl, terdiri dari solar dan minyak tanah 14,39 juta kl, Premium 8,44 juta kl, dan BBM non subsidi 41,13 juta $\mathrm{kl}$, diprediksi naik $15 \%$ pada tahun 2021, akan menyentuh 75 juta kl atau rata-rata 1,23 juta bph.

BBM untuk kendaraan bermotor berasal dari minyak bumi yang merupakan 
salah satu dari bahan bakar fosil selain batu bara dan gas alam. Bahan bakar fosil adalah sumber energi tak terbarukan (nonrenewable energy), suatu saat bahan bakar ini akan habis, diperkirakan 53 tahun ke depan dunia akan kehabisan minyak bumi.

Meskipun pemanfaatan minyak bumi sebagai sumber energi bagi kendaraan bermotor dengan emisi gas $\mathrm{CO}_{2}$ hasil pembakaran akan meningkatkan gas rumah kaca (Chen, Gonder, Young, \& Wood, 2019) sehingga akan terjadi pemanasan global, namun mobil dan sepeda motor saat ini masih bergantung pada BBM (premium, pertalit dan solar) (Rozikin \& Firdaus, 2021). Penghematan konsumsi BBM pada kendaraan adalah cara yang tepat untuk menyikapi bahan bakar fosil sebagai sumber energi yang tak terbarukan dan salah satu penyebab efek rumah kaca.

Di dalam usaha penghematan konsumsi bahan bakar, beberapa pabrikan kendaraan bermotor melakukan riset sehingga menghadirkan teknologi yang mampu menghemat konsumsi bahan bakar. Sistem injeksi secara elektrik menggantikan sistem karburator, mampu menekan konsumsi bahan bakar (Prihartono, 2020).

Penggunaan turbo charger diperoleh penghematan bahan bakar, karena daya yang dihasilkan lebih besar, walaupun diameter silindernya lebih kecil (Wigraha, 2015). Pemilihan jenis material yang lebih ringan untuk komponen motor bakar dan juga di bagian bodi kendaraan, sehingga dapat lebih meningkatkan efisiensi bahan bakar (Gv- \& Wijianti, 2018). Desain pengaturan udara dan bahan bakar perlu disempurnakan, seperti teknologi VVT-I yang diklaim lebih lebih efisien (Qosim, 2020).

Upaya penghematan bahan bakar melalui teknologi yang diaplikasi pada kendaraan bermotor oleh pabrikan tidak akan optimal jika tidak diikuti dengan perawatan kendaraan bermotor, salah satunya adalah perawatan yang terkait dengan filter udara, karena kondisi filter udara akan mempengaruhi kinerja mesin, dimana untuk mendapatkan pembakaran sempurna maka diperlukan filter yang dapat menyaring debu atau kotoran-kotoran dan berfungsi sebagai penyaring gas-gas yang tidak diperlukan dalam proses pembakaran (Fatkhuniam, Wijaya, \& Septiyanto, 2018).

Filter yang kotor tidak dapat berfungsi secara sempurna, udara yang masuk ke ruang akar jadi lebih sedikit menyebabkan kinerja mesin tidak optimal. Sumbatan pada filter dapat mengakibatkan timbul kotoran yang masuk ke ruang bakar, sehingga menghambat supply udara di ruang bakar. Jika itu terjadi, maka beban tenaga di ruang bakar terhambat. Hal ini menyebabkan harus mengeluarkan tenaga lebih besar sehingga bahan bakar menjadi lebih boros dibanding keadaan normal. Dengan alasan ini, maka pabrikan memberikan pedoman perawatan berkala untuk membersihkan atau mengganti filter udara, seperti penggantian filter udara setiap $16.000 \mathrm{~km}$ untuk Honda Beat.

Berdasarkan uraian di atas, Penelitian ini bertujuan untuk mengetahui kinerja mesin dan konsumsi bahan bakar dengan variasi kondisi beberapa filter udara yang berbeda menurut jarak tempuh, serta dapat menjelaskan pentingnya mengganti filter udara, tidak cukup hanya membersihkan.

\section{METODE PENELITIAN}

Tahap pertama proses penelitian ini dimulai dengan mempersiapkan objek penelitian yaitu Honda Beat Esp tahun 2019 yang baru tune up dan penggantian beberapa komponen seperti oli mesin, oli gear box, busi dan belt drive kit. Persiapan yang lain adalah filter udara genuine part dengan part number $17210 \mathrm{~K} 16900$ yang sampelnya diambil dari motor yang biasa dikendarai di perkotaan, yaitu di kota Bandar Lampug, dengan tingkat kekotoran filter yang berbeda, seperti terlihat pada Tabel 1. 
Tahap kedua adalah pengujian kinerja mesin, dimulai dengan menempatkan motor di mesin dynamometer yang dilengkapi dengan layar monitor yang akan menampilkan parameter yang diukur, seperti yang terlihat pada Gambar 1 . Adapun parameter yang dianalisis dalam penelitian ini adalah perubahan daya (hp), torsi (ft.lbs). Pengujian dilakukan sebanyak 4 kali, masing-masing adalah pengujian dengan menggunakan filter udara $0 \mathrm{~km}$, filter udara $4.000 \mathrm{~km}$, filter udara $8.000 \mathrm{~km}$, filter udara $12.000 \mathrm{~km}$, dan filter udara $16.000 \mathrm{~km}$.

Tabel 1. Sampel Filter Udara

\begin{tabular}{|c|c|c|}
\hline No & Usia Pakai Filter & Gambar \\
\hline 1 & $0 \%$ & \\
\hline 2 & $4.000 \mathrm{~km}$ & \\
\hline 3 & $8.000 \mathrm{~km}$ & \\
\hline 4 & $12.000 \mathrm{~km}$ & \\
\hline 5 & $16.000 \mathrm{~km}$ & \\
\hline
\end{tabular}

Tahap ketiga adalah pengujian konsumsi bahan bakar, dimana pengujian menggunakan metode Full to Full / Top $U p$, dengan berat pengendara $60 \mathrm{~kg}$, type bukaan gas yang soft dan kondisi jalan datar perkotaan. Adapun bahan yang digunakan adalah BBM jenis Pertalite dan gelas ukur.

Tahap keempat atau tahap terakhir adalah analisis data, dimana data hasil pengujian disajikan dalam bentuk grafik dan dideskripsikan.

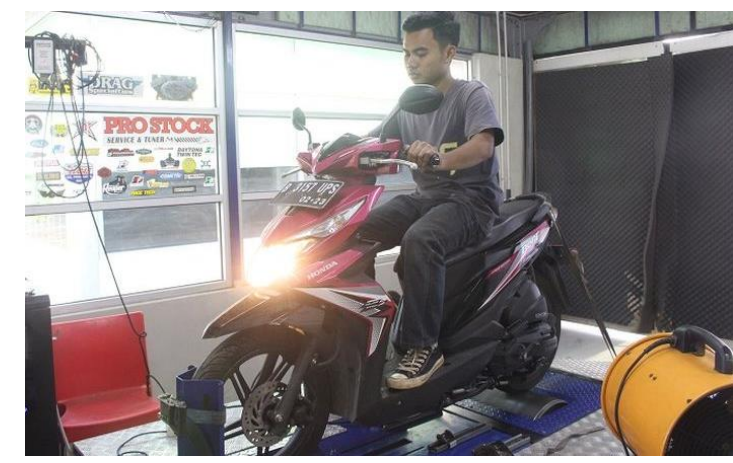

Gambar 1. Pengujian Kinerja Mesin

\section{HASIL DAN PEMBAHASAN}

Data hasil pengujian kinerja mesin pada parameter daya (hp), seperti yang disajikan pada Gambar 2, terjadi penurunan daya setiap perubahan kondisi pakai filter udara, dengan penurunan daya pada kondisi pakai filter udara pada $16000 \mathrm{~km}$ sebesar $8.28 \%$.

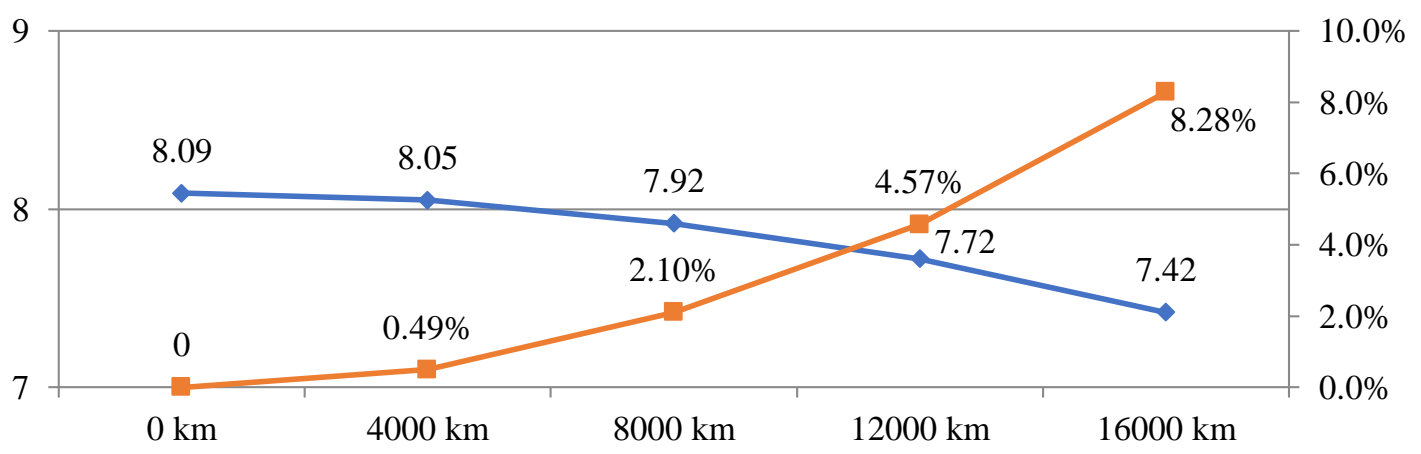

$\multimap$ Daya (hp) $\quad-$ Penurunan kinerja

Gambar 2. Hasil pengujian daya (hp) 
Data hasil pengujian kinerja mesin pada parameter torsi (hp), seperti yang disajikan pada Gambar 3, terjadi penurunan torsi setiap perubahan kondisi pakai filter udara. dengan penurunan daya pada kondisi pakai filter udara pada 16000 km sebesar $1,25 \%$.
Data hasil pengujian konsumsi bahan bakar, seperti yang telihat pada Gambar 4, terlihat bahwa terjadi peningkatan konsumsi bahan bakar seiring dengan perubahan kondisi pakai filter, konsumsi bahan bakar meningkat $2.83 \%$ jika dibandingkan pada kondisi filter udara 0 $\mathrm{km}$ atau dalam keadaan baru

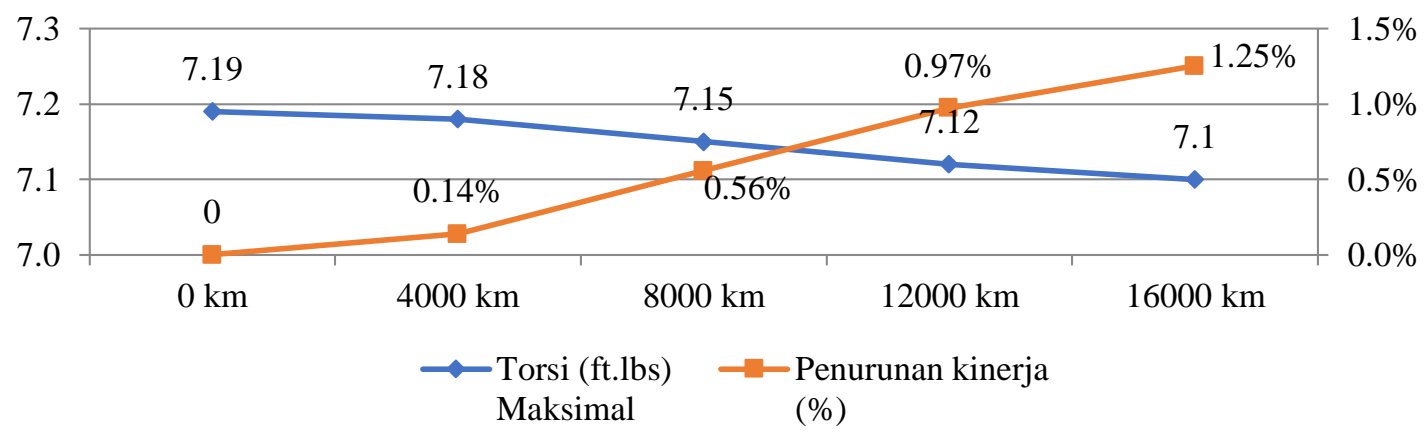

Gambar 3. Hasil pengujian torsi (ft.lbs)

Pada kondisi filter $0 \mathrm{~km}$ atau pada seiring dengan perubahan kondisi filter kondisi baru, jarak tempuh dalam 1 liter hingga jarak tempuh $56.5 \mathrm{~km}$ pada kondisi $\mathrm{BBM}$ adalah 58,1 km dan terus menerus filter $16000 \mathrm{~km}$.

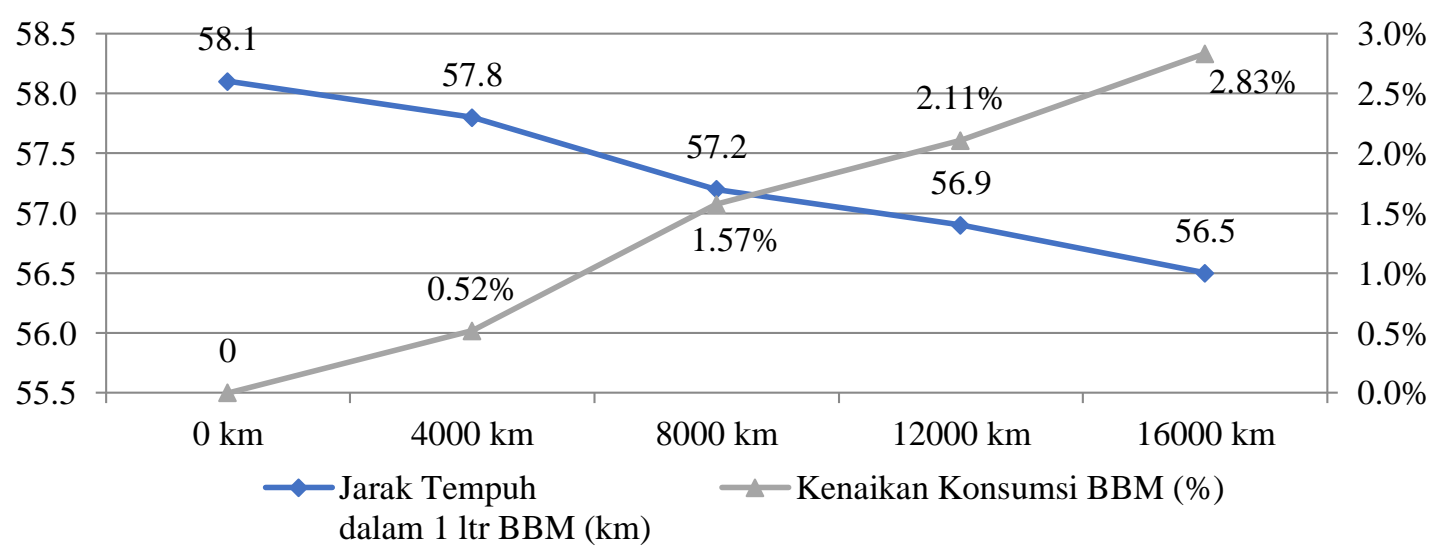

Gambar 4. Hasil pengujian konsumsi bahan bakar

Penumpukan kotoran yang terakumulasi membuat asupan ke ruang bakar semakin berkurang seiring semakin kotornya filter udara, sehingga pembakaran menjadi tidak maksimal. Membersihkan filter pada setiap $4000 \mathrm{~km}$ seperti yang disarankan dalam perawatan periodik tidak mampu mengembalikan kinerja mesin seperti semula, sehingga filter udara harus diganti, tidak cukup hanya dibersihkan.

\section{KESIMPULAN}

Pada pengujian parameter terjadi penurunan kinerja mesin seiring kondisi pakai filter udara, dimana terjadi penurunan 
daya sebesar $8.28 \%$ dan penururan torsi sebesar 1,25\%. Sementara itu, pada pengujian konsumsi bahan bakar, terjadi peningkatan konsumsi sebesar 2,83\% jika dibandingkan pada kondisi filter udara 0 $\mathrm{km}$ atau dalam keadaan baru. Selain itu, filter udara harus diganti, tidak cukup hanya dibersihkan.

\section{DAFTAR PUSTAKA}

Chen, Y., Gonder, J., Young, S., \& Wood, E. (2019). Quantifying autonomous vehicles national fuel consumption impacts: A data-rich approach. Transportation Research Part A: Policy and Practice, 122(xxxx), 134 145. doi:10.1016/j.tra.2017.10.012

Fatkhuniam, A., Wijaya, M. B. R., \& Septiyanto, A. (2018). Perbandingan Penggunaan Filter Udara Standar dan Racing Terhadap Performa dan Emisi Gas Buang Mesin Sepeda Motor Empat Langkah. Jurnal Dinamika Vokasional Teknik Mesin, 3(2), 130 137.

doi:10.21831/dinamika.v3i2.21410

Gv-, H. E. T., \& Wijianti, E. S. (2018). Pengaruh Material Bearing Terhadap Konsumsi Bahan Bakar MOBIL Jurusan Teknik Mesin , Fakultas Teknik , Universitas Bangka Balitung
Kampus Terpadu Desa Balunijuk Kecamatan Merawang Kabupaten bangka 21 Wijianti, Eka Sari, dkk; Pengaruh Material Bearing $\mathrm{T}$. Machine;Jurnal Teknik Mesin, 4(2), 21-24.

Prihartono, J. (2020). Perbedaan Pengaruh Sistem Injeksi Bahan Bakar Elektrik Dengan dan Tanpa Dilengkapi Sistem Pengaturan Waktu Buka Tutup Katup, Terhadap Peforma Mesin, Konsumsi Bahan Bakar dan Emisi Gas Buang. Presisi, 22(1), 10-17.

Qosim, N. (2020). Jurnal Pendidikan Teknik Mesin Undiksha, 8(2), 53-61. doi:10.23887/jptm.v9i1.

Rozikin, N. A., \& Firdaus, R. (2021). Effect Of Additional Variations Of Etanol Fuel On Exhaust Gas Emissions On Yamaha 125cc Motorcycles. Academia Open, 4, 1-9. doi:10.21070/acopen.4.2021.1969

Wigraha, N. A. (2015). Teknologi Motor Bakar Bensin Untuk Mencapai Persyaratan Batas Maksimal Polusi Dan Efisiensi Pemakaian Bahan Bakar Bensin. Jurnal Pendidikan Teknologi Dan Kejuruan, 12(2). doi:10.23887/jptk.v12i2.6479 